\title{
Global gene expression profile of cerebral ischemia-reperfusion injury in rat MCAO model
}

\author{
Chunmei Wang ${ }^{1}$, Minghui Liu ${ }^{1}$, Yanyou Pan ${ }^{1}$, Bo Bai ${ }^{1}$ and Jing Chen ${ }^{1,2}$ \\ ${ }^{1}$ Neurobiology Institute, Jining Medical University, Jining 272067, P.R. China \\ ${ }^{2}$ Division of Biomedical Sciences, Warwick Medical School, University of Warwick, Coventry CV4 7AL, U.K. \\ Correspondence to: Bo Bai, email: bbai@mail.jnmc.edu.cn \\ Jing Chen, email: Jing.Chen@warwick.ac.uk \\ Keywords: gene expression profile, ischemia-reperfusion injury, MCAO model, RNA sequencing \\ Received: March 23, $2017 \quad$ Accepted: June 30, $2017 \quad$ Published: August 14, 2017 \\ Copyright: Wang et al. This is an open-access article distributed under the terms of the Creative Commons Attribution License 3.0 \\ (CC BY 3.0), which permits unrestricted use, distribution, and reproduction in any medium, provided the original author and source \\ are credited.
}

\section{ABSTRACT}

It is well-established that reperfusion following cerebral ischemic injury gives rise to secondary injury accompanied by structural and functional damage. However, it remains unclear how global genes changes in cerebral ischemia-reperfusion injury (IRI). This study investigated global gene expression in the hippocampi of Wistar rats following transient cerebral IRI using an RNA-sequencing strategy. The results revealed $\geq 2$-fold up-regulation of 156 genes and $\geq 2$-fold down-regulation of 26 genes at $24 \mathrm{~h}$ post-reperfusion. Fifteen differentially expressed genes were selected to confirm the RNA-sequencing results. Gene expression levels were dynamic, with the peak expression level of each gene occurring at different time points postreperfusion. Gene Ontology (GO) analysis classified the differentially expressed genes as mainly involved in inflammation, stress and immune response, glucose metabolism, proapoptosis, antiapoptosis, and biological processes. KEGG pathway analysis suggested that IRI activated different signaling pathways, including focal adhesion, regulation of actin cytoskeleton, cytokine-cytokine receptor interaction, MAPK signaling, and Jak-STAT signaling. This study describes global gene expression profiles in the hippocampi of Wistar rats using the middle cerebral artery occlusion (MCAO) model. These findings provide new insights into the molecular pathogenesis of IRI and potential drug targets for the prevention and treatment of IRI in the future.

\section{INTRODUCTION}

Ischemic stroke is one of the leading causes of death and disability worldwide, making its prevention and treatment urgent. Evidence from clinical trials suggests that the most effective treatment currently available is thrombolysis therapy $[1,2]$. However, reperfusion after thrombolysis may further exacerbate cerebral ischemic injury by disrupting cerebral microvascular endothelial cells, a phenomenon referred to as cerebral ischemia-reperfusion injury (IRI) [3, 4]. Currently, there is no approved therapy for the treatment of IRI.

The mechanisms of cerebral IRI are complex. During reperfusion, blood flow is reintroduced to the tissue, triggering a series of events including oxidative stress, energy failure, inflammation, excitatory amino acids toxicity, the activation of various cell-signaling pathways, apoptosis, and neuronal death $[5,6]$. Meanwhile, the ischemia-reperfusion process usually lead to increase or decrease of a number of genes, such as insulin-like growth factor-1 (IGF-1)[7], heat shock protein (HSP27) [8], protein tyrosine kinase type 2 beta (Ptk2b) [9], high mobility group box 1 (HMGB1) [10], and pyruvate dehydrogenase kinase 4 (PDK4) [11]. We hypothesize that the process of reperfusion induces the abnormal expression of a large number of genes. This altered gene expression might activate or suppress corresponding signaling pathways, resulting in cellular necrosis or apoptosis.

In the present study, we describe changes in global gene expression in rat hippocampi after cerebral IRI. These results provide new insights into understanding the mechanisms of cerebral IRI. Furthermore, the identified 
genes may be considered potential drug targets for the prevention and treatment of cerebral IRI.

\section{RESULTS}

\section{IRI induces cerebral infarct}

The infarct areas appeared white when stained with TTC. As shown in Figure 1, brain tissue in the sham group appeared uniform red in color, indicating no infarction. After the right cerebral hemisphere was subjected to ischemia and reperfusion, the infarct volume was increased $33.64 \% \pm 2.06 \%$ compared with the sham group. This result demonstrated that IRI induced cerebral infarct, indicating that the model was successful.

\section{Global gene expression profile of IRI}

A global gene expression profile provides comprehensive insights into which hippocampal genes participate in the pathology of cerebral IRI. Genes with similar expression patterns often have a functional correlation. We carried out cluster analysis of gene expression patterns using cluster and java Treeview software. There were significant differences in cluster analysis between the sham group and the IRI/24 h group (Figure 2A). The genes with increased expression were

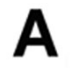

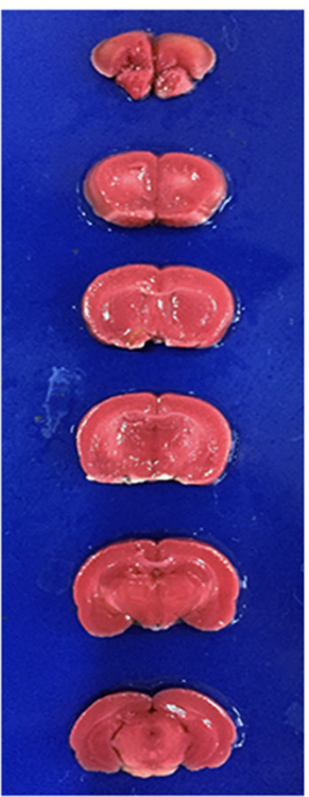

Sham

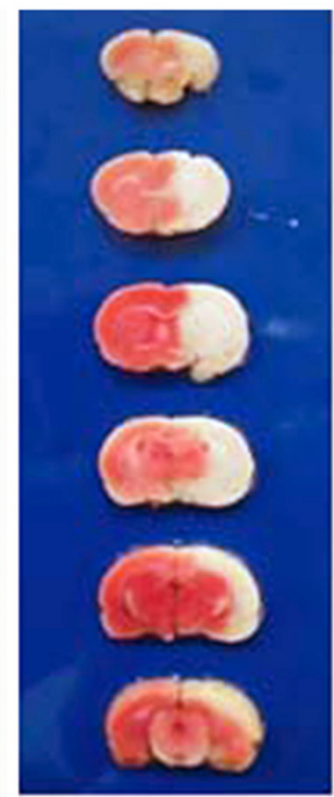

IRI divided into four groups. Genes with decreased expression were divided into six groups.

182 genes demonstrated differential expression in the IRI/24 $\mathrm{h}$ group relative to the sham group. As shown in Figure 2B, 156 genes were significantly up-regulated in the IRI/24 h group when compared with the sham group, and 26 genes were significantly down-regulated. There was a more than 2-fold change in expression levels of the indicated genes in the IRI/24 h group relative to the sham group. It is likely that these 182 genes involve in the pathology of IRI, and their annotation will help to further elaborate the molecular mechanism of IRI. A portion of the differentially expressed genes are listed in Table 1.

\section{Confirmation of differentially expressed genes by RT-PCR}

To confirm the results obtained from RNA sequencing, we examined the expression of representative genes at the mRNA level using RT-PCR (Figure 3). The sequences of all primers used are listed in Tables 2 and 3 . The genes belonging to the heat shock protein (Hsp) family were selected for amplification because their expression showed the most significant up-regulation in the RNA-sequencing studies. As shown in Figure $3 \mathrm{~A}$, expression of Hspb1, Hspala, and Hspa1b was significantly increased in the IRI/24 h group compared
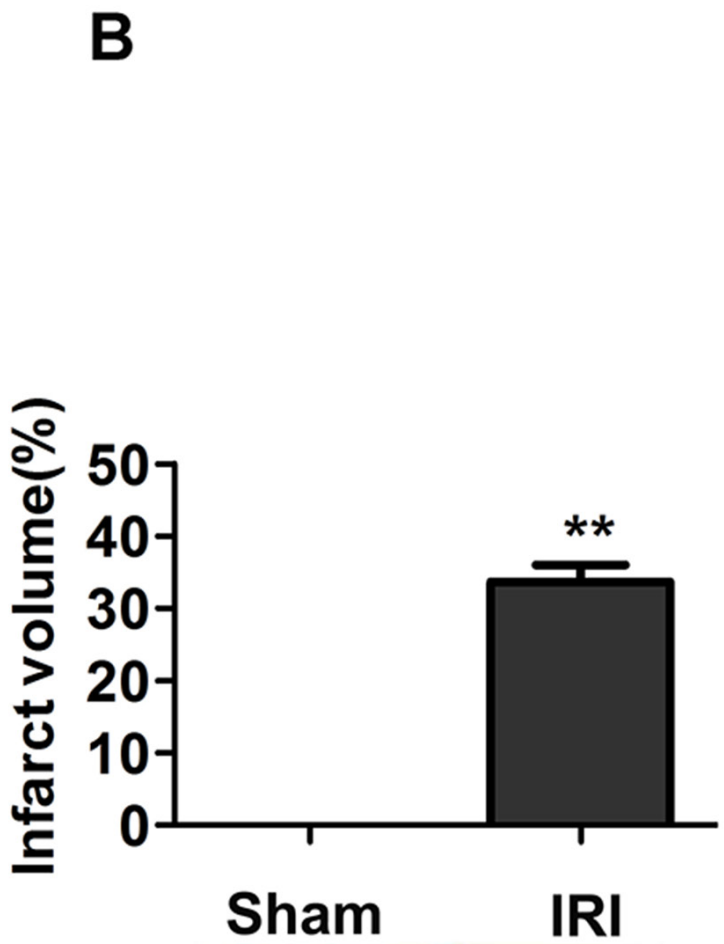

Figure 1: Infarct volume in sham and IRI/24 h groups determined by TTC staining. (Panel A) Representative coronal brain sections of the sham and IRI/24 h groups. Brain sections in the sham group showed no infarction. The infarct volumes in the IRI/24 h group were significantly increased compared with those in the sham group. (Panel B) Percentage of cerebral infarct volume to total brain volume. The percentage of infarct volume was approximately $33.6 \%$ at $24 \mathrm{~h}$ in the IRI model. $* * P<0.01$. 

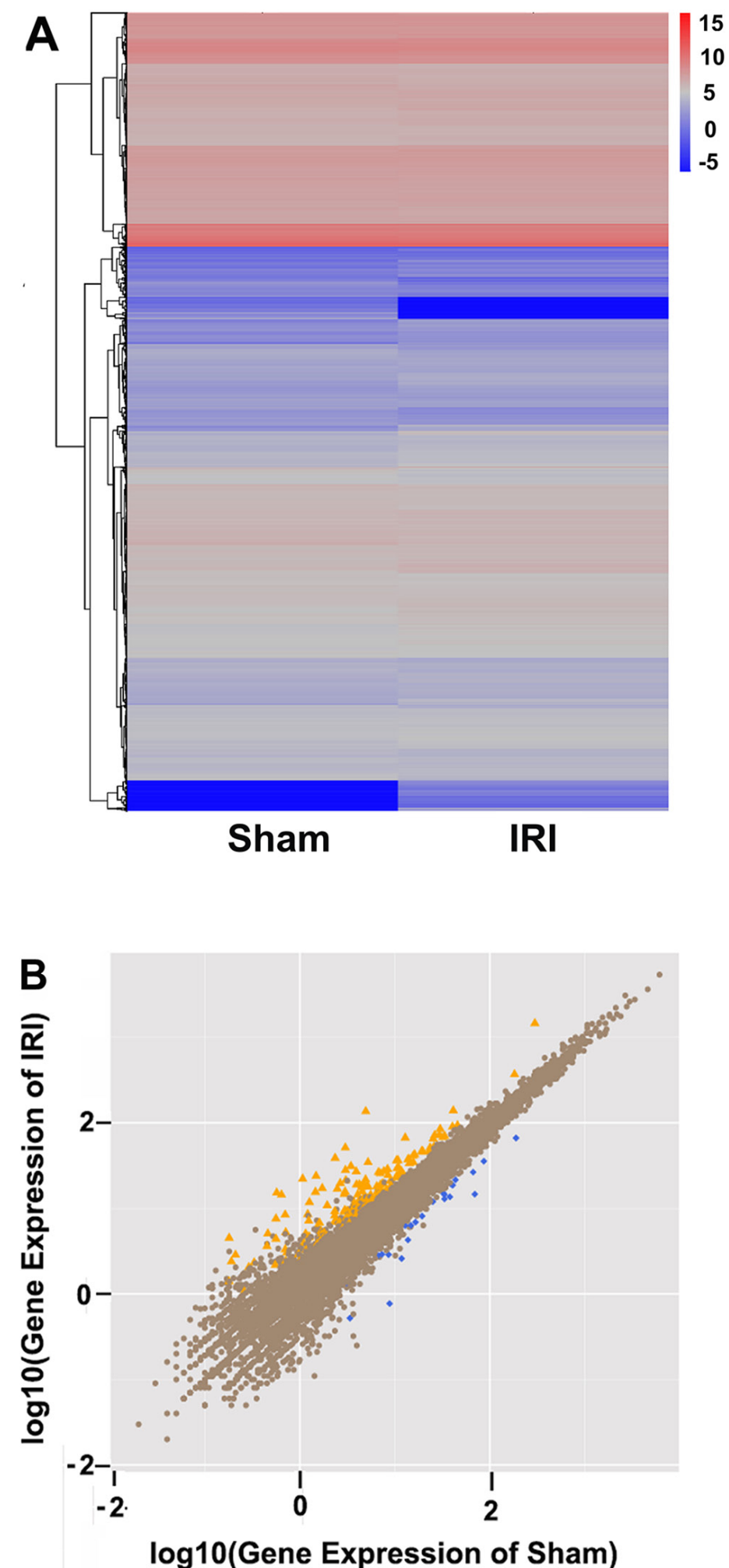

Figure 2: Comparison between sham and IRI/24 h groups by RNA sequencing. (Panel A) The differentially expressed genes between the sham group $(n=6)$ and the IRI/24 h group $(n=6)$ were analyzed using SAM software and visualized with Treeview tools upon hierarchical clustering. A colored tag represents gene expression levels. Red spectrum denotes up-regulated genes, and blue denotes down-regulated genes. (Panel B) Scatter plot display of the differentially expressed genes between sham and IRI groups. The X and Y axes represent the $\log 2$ fold change in gene expression. Yellow points represent the up-regulated genes with fold change less than 1 and $P<0.05$. Blue points denote the down-regulated genes with fold change greater than 1 and $P<0.05$. Brown points indicate genes in which there were no significant differences in expression. 
Table 1: Genes differentially expressed between sham and IRI/24 h groups

\begin{tabular}{|c|c|c|c|}
\hline Gene ID & Description & Symbol & Fold change \\
\hline 24471 & heat shock protein $\mathrm{B} 1$ & Hspb1 & 10.84648 \\
\hline 24498 & interleukin 6 & IL-6 & 10.40939 \\
\hline 25544 & selectin E & Sele & 7.965784 \\
\hline 89829 & suppressor of cytokine signaling 3 & Socs3 & 7.267831 \\
\hline 307351 & tubulin, beta 6 class $\mathrm{V}$ & Tubb6 & 6.173174 \\
\hline 24472 & heat shock $70 \mathrm{kD}$ protein $1 \mathrm{~A}$ & Hspala & 4.493855 \\
\hline 24577 & myelocytomatosis oncogene & Myc & 3.284498 \\
\hline 680611 & B-cell CLL/lymphoma 3 & $\mathrm{Bcl} 3$ & 2.885765 \\
\hline 24887 & Bcl2-associated X protein & Bax & 2.819229 \\
\hline 314322 & FBJ osteosarcoma oncogene & Fos & 2.981011 \\
\hline 304962 & activating transcription factor 6 & Atf6 & 2.781895 \\
\hline 24387 & glial fibrillary acidic protein & Gfap & 2.479572 \\
\hline 24451 & heme oxygenase (decycling) 1 & Hmox 1 & 2.285812 \\
\hline 308995 & integrin, alpha L & Itgal & 2.165753 \\
\hline 361321 & autophagy related 12 & $\operatorname{Atg} 12$ & 3.980192 \\
\hline 84398 & CD93 molecule & $\mathrm{Cd} 93$ & 3.581731 \\
\hline 60350 & CD14 molecule & CD14 & 2.475128 \\
\hline 83785 & vascular endothelial growth factor A & Vegfa & 2.773833 \\
\hline 497942 & chemokine ligand 16 & Cxcl16 & 2.54374 \\
\hline 315609 & CD3 molecule, epsilon & $\mathrm{Cd} 3 \mathrm{e}$ & -6.21785 \\
\hline 292843 & sialic acid-binding Ig-like lectin 5 & Siglec5 & -5.69617 \\
\hline 299757 & neurotensin & Nts & -4.54653 \\
\hline 83725 & Wolfram syndrome 1 (wolframin) & $\mathrm{Wfs} 1$ & -2.85056 \\
\hline 24224 & B-cell CLL/lymphoma 2 & Bcl-2 & -1.68324 \\
\hline
\end{tabular}

with the sham group with a fold change of $4.06,2.43$, and 20.88 , respectively (Figure $3 \mathrm{E}, * * P<0.01, * * * P<0.001$ ). Two genes, Atf6 and Chop2, related to endoplasmic reticulum (ER) stress, were also significantly up-regulated in IRI/24 h (Figure 3B). The fold change in the IRI/24 h group relative to the sham group of Atf6 and Chop2 was 1.69 and 1.33 , respectively (Figure $3 \mathrm{~F}, * P<0.05$ ). The expression of Wfs 1 , another gene related to ER stress, was down-regulated 2.4-fold (Figure $3 \mathrm{~F}, * * P<0.01$ ) in the IRI/24 h group. Three genes, calreticulin, Atg3, and Atg12, were related to autophagy. Their relative mRNA levels were significantly higher with fold changes of 2.13, 3.25, and 2.36, respectively. (Figure $3 \mathrm{C}$ and $3 \mathrm{G}, * P<0.05$, $* * P$ $<0.01)$. The expression of Bcl-2 was lower, while the mRNA levels of Bax and Caspase-12 were higher, in the IRI/24 h group than in the sham group (Figure $3 \mathrm{D}$ and $3 \mathrm{H}$, $* P<0.05, * * P<0.01)$. These results were consistent with the sequencing results.
To understand the expression of the above genes in the OGD cell model, we compared their expression between the OGD model and the control model. As shown in Figure 4, the expression trends of these genes in the OGD model were consistent with the trends in the animal models. The up-regulated genes were Hspb1, Hspa1a, Hspa1b, Atf6, Chop2, calreticulin, Atg3, Atg12, Bax, and Caspase-12. The down-regulated genes were Wfs 1 and $\mathrm{Bcl}-2$. The results obtained using RT-PCR were consistent with the results obtained by RNA sequencing.

\section{Gene expression patterns vary over the course of IRI}

In addition, we detected the expression of several genes at different times post-reperfusion. As shown in Figure 5, the expression patterns of four genes displayed significant differences at various times during the post- 
A

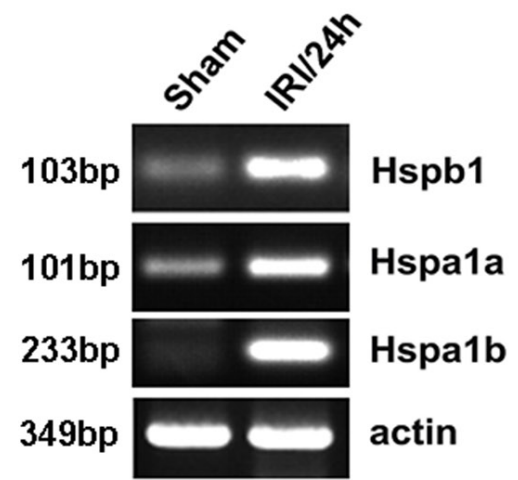

C
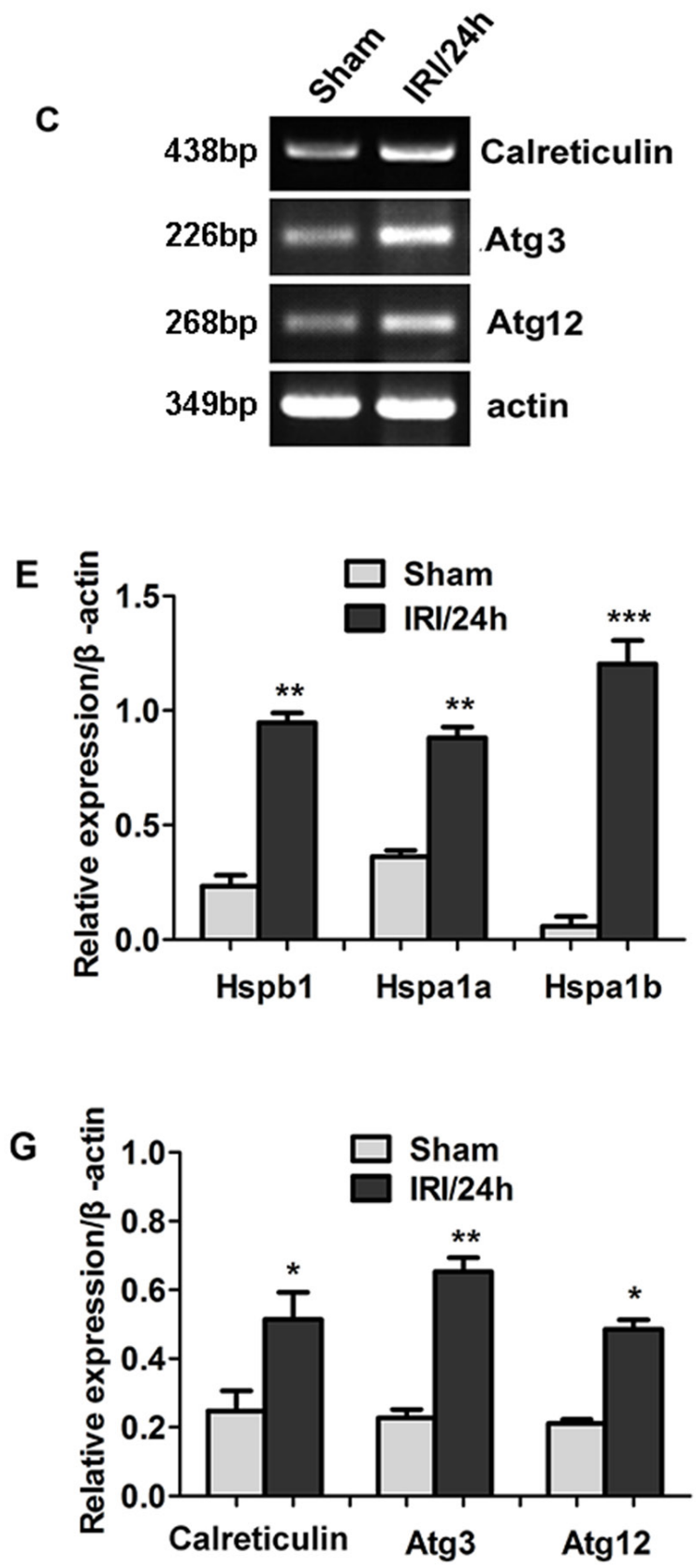

B

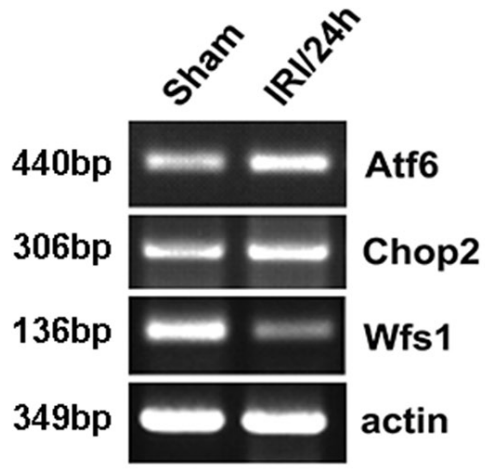

D

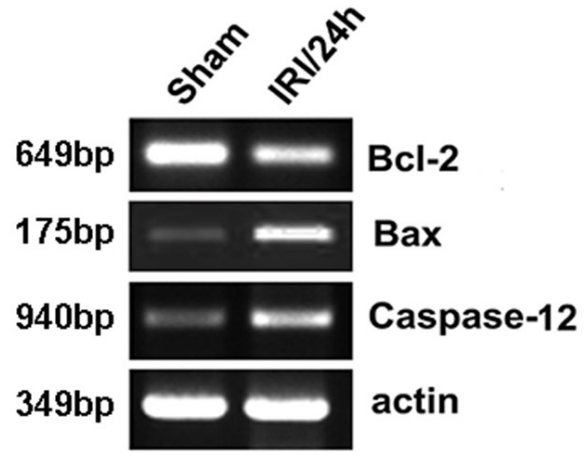

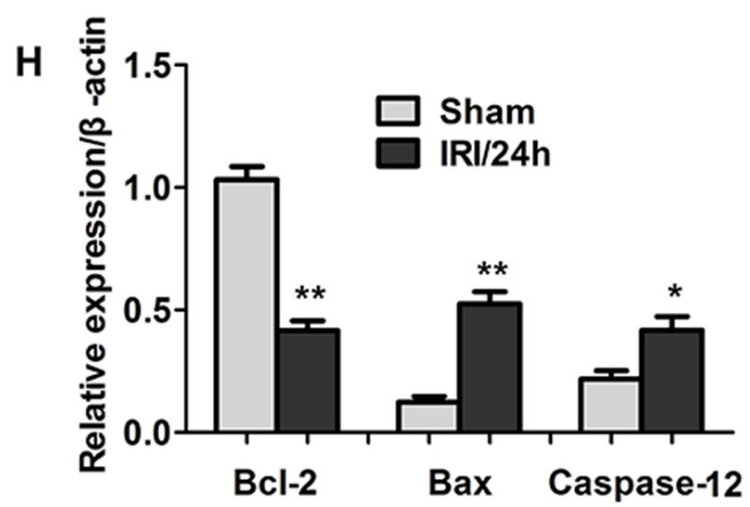

Figure 3: Differential gene expression between sham and IRI/24 h groups was detected by RNA sequencing. (Panel A-D) Representative images of RT-PCR confirming differential gene expression. (Panel E-H) Quantitative analysis of gene expression. ${ }^{*} P<$ $0.05,{ }^{* *} P<0.01, * * * P<0.001$ vs sham. 
Table 2: Primer sequences used for gene amplification in the rat model

\begin{tabular}{|c|c|c|}
\hline Primer names & Forward sequences $\left(5^{\prime}-3^{\prime}\right)$ & Reverse sequences $\left(5^{\prime}-3^{\prime}\right)$ \\
\hline$\beta$-actin & tggaatcctgtggcatccatgaac & taaaacgcagctcagtaacagtccg \\
\hline Hspala & gagggtctcaagggcaagat & ttctcagccagcgtgttaga \\
\hline Hspa1b & tctaacacgctggctgagaa & agcagccatcaagagtctgt \\
\hline Hspb1 & acgaagaaaggcaggatgaa & gacagggaagaggacaccag \\
\hline Atf6 & cccaccaaaggtcagactgt & cttgggactttgagcctctg \\
\hline Chop2 & agcagaggtcacaagcacct & acagttcatgcttggtgcag \\
\hline Wfs 1 & cagccgagaagggacagata & ggcaagtcgcaggtagtgtt \\
\hline Calreticulin & gaatggaagccacgtcaaat & tggcetctacagctcatcct \\
\hline Atg3 & cggtcctcaaggaatcaaaa & gcctccaattcatccgaata \\
\hline $\operatorname{Atg} 12$ & aagatggcagaagacccaga & tgaagtcgatgagtgcttgg \\
\hline $\mathrm{Bcl}-2$ & aagctgtcacagaggggcta & ctcacttgtggeccaggtat \\
\hline Bax & ctgcagaggatgattgctga & gatcagctcgggcactttag \\
\hline Caspase-12 & gctgccaagagaacacatga & tccetttgcttgtggatacc \\
\hline Canx & gatgctgtcaagccagatga & ttagggttggcaatctgagg \\
\hline Cacnale & gccettaaagctcgtgtcag & gcattggaagacagtcagca \\
\hline Slc24a2 & ccgaggaagatgatgaccag & tccagagagggaacacgatg \\
\hline $\operatorname{Ttr}$ & actggaaggctcttggcatt & gctgtaggagtacgggctga \\
\hline
\end{tabular}

Table 3: Primer sequences used for gene amplification in the cell model

\begin{tabular}{|c|c|c|}
\hline Primer names & Forward sequences $\left(5^{\prime}-3^{\prime}\right)$ & Reverse sequences ( $\left.5^{\prime}-3^{\prime}\right)$ \\
\hline$\beta$-actin & acactgtgcccatctacgagggg & atgatggagttgaaggtagtttcgtggat \\
\hline Hspala & gatcaacgacggagacaagc & gctgcgagtcgttgaagtag \\
\hline Hspa1b & gatcaacgacggagacaagc & gctgcgagtcgttgaagtag \\
\hline Hspb1 & ccaagtttcetcctccetgt & ggtgactgggatggtgatct \\
\hline Atf6 & gcagaacctcagccactttc & gctgctggaagcaataaagg \\
\hline Chop2 & tcttgaccetgettctctgg & getgtgccactttcctttca \\
\hline Wfs 1 & ccctacctggtgtgettcat & gagctccagagacgtgaacc \\
\hline Calreticulin & ccccagtgattcagaaccet & gccaaactcctcagcgtatg \\
\hline Atg3 & acggcagcctttaacagttg & cttcatcacctcagcatgcc \\
\hline $\operatorname{Atg} 12$ & ctggaggggaaggacttacg & gggaaggagcaaaggactga \\
\hline Bcl-2 & gggtacgataaccgggagat & ctgaagagctcctccaccac \\
\hline Bax & ggggacgaactggacagtaa & cagttgaagttgccgtcaga \\
\hline Caspase-12 & caagcactgggatcaagag & aaccaaacaatcccagcacc \\
\hline
\end{tabular}

reperfusion period. The expression of the Canx gene was highest at $6 \mathrm{~h}$ post-reperfusion, and then gradually decreased. The Cacnale gene reached its highest expression levels at $12 \mathrm{~h}$ post-reperfusion, then decreased. The expression of Slc24a2 first decreased, then gradually increased, peaked $24 \mathrm{~h}$ post-reperfusion, then decreased once more. Ttr gene expression was reduced during the first $12 \mathrm{~h}$ post-reperfusion, but was dramatically raised at $24 \mathrm{~h}$ and $48 \mathrm{~h}$ post-reperfusion. These results demonstrate that the patterns of gene expression are complex and diverse, increasing the difficulty of understanding the molecular pathology of IRI. 

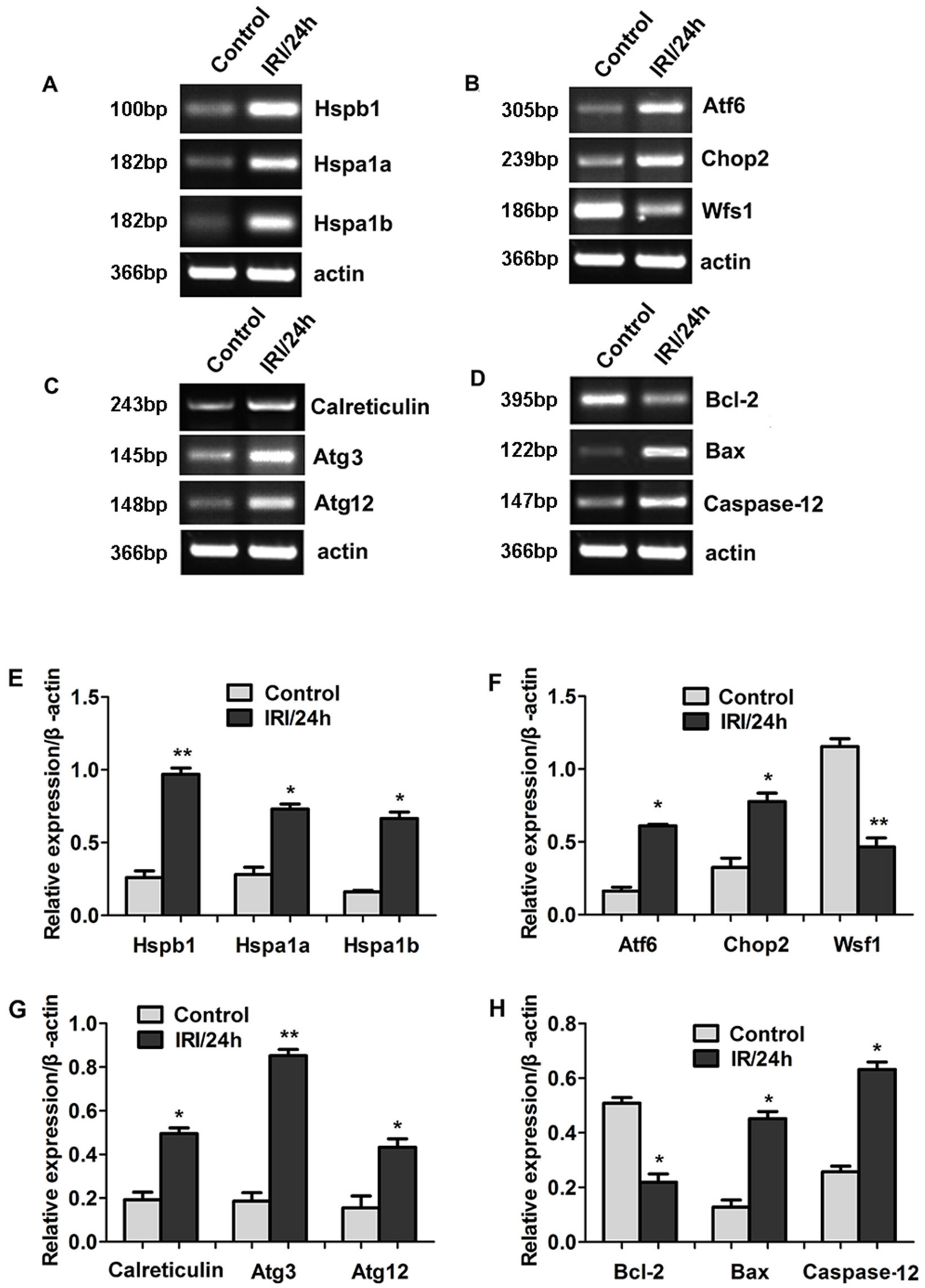

Figure 4: Differential gene expression between OGD cell model and control was detected by RNA sequencing. (Panel A-D) Representative images of RT-PCR confirming the differential gene expression. (Panel E-H) Quantitative analysis of gene expression. $* P<0.05, * * P<0.01$ vs control. 


\section{Elevation of TNF- $\alpha$, IL-6, and Icam-1 levels in} rat and cell models

The expression of proinflammatory factors and adhesion molecules was detected using ELISA. As shown in Figure 6A, the levels of TNF- $\alpha$, IL-6, and ICAM-1 in the hippocampi of the IRI/24 h group were all higher than the levels in the hippocampi of the sham group. TNF- $\alpha$ was increased by 2.62 -fold ( $2.04 \pm 0.42$ vs $0.78 \pm 0.07$ ng/g), IL-6 by 2.86 -fold ( $2.66 \pm 0.16$ vs $0.93 \pm 0.41 \mathrm{ng} / \mathrm{g}$ ), and Icam- 1 by 3.95 -fold $(111.72 \pm 3.69$ vs $28.29 \pm 1.64$ $\mathrm{ng} / \mathrm{g}$ ). The levels of TNF- $\alpha$, IL-6, and ICAM-1 were also detected in the OGD cell model (Figure 6B). TNF- $\alpha$, IL6 , and ICAM-1 were up-regulated with fold increases of $2.13(1.11 \pm 0.07$ vs $0.52 \pm 0.06 \mathrm{ng} / \mathrm{g}), 1.73(1.96 \pm 0.14$ vs $1.13 \pm 0.11 \mathrm{ng} / \mathrm{g})$, and $1.79(44.08 \pm 2.71 \mathrm{vs} 24.63 \pm 2.63$ $\mathrm{ng} / \mathrm{g}$ ), respectively, compared with the sham group. These findings indicate that reperfusion following ischemic injury promotes the activation of inflammatory factors and adhesion molecules.

\section{GO analysis of biological functions of differentially expressed genes}

To elucidate the roles of differentially expressed genes, GO analysis was used to analyze the biological functions of those genes. As shown in Table 4 and Figure 7 , the differentially expressed genes were divided into three functional groups. In the biological process group, the top four categories were single-organism processes, cellular processes, response to stimulus, and biological regulation. The genes belonging to these categories were Atf3, Ssc5d, Lgals3, Olr1, Sema3d, Pter, Myd88, Selplg, and $\mathrm{Wfs} 1$. They are involved in responding to various stimuli, metabolic processes, the inflammatory response, and cell signaling. In the molecular function group, the identified categories were binding and activation. Genes belonging to this category were Igfbp2, Fibcd1, Socs3, Gfap, Pla1a, and Cd3e. They are involved in growth factor binding, carbohydrate derivative binding, protein kinase regulator activity, structural molecule activity, catalytic activity, and signaling receptor activity. The cellular components group categories included cell, cell part, membrane components, and organelles. The genes Abca4, Tspo, and Siglec5 belonged to the membrane components category. These results suggest that IRI induces abnormalities of biological processes, molecular function, and cellular components.

\section{Pathway analysis of differentially expressed genes}

KEGG pathway analysis was used to provide a more in-depth understanding of the biological functions of the differentially expressed genes. Pathways that were significantly induced after cerebral IRI are listed in Table 5. This analysis suggests that the cellular pathways involved in IRI include focal adhesion, regulation of the actin cytoskeleton, cytokine-cytokine receptor interaction, MAPK signaling, Jak-STAT signaling, cell adhesion molecules, and ER stress. Figure 8 shows two significantly induced pathways, ER stress signaling and autophagy. In the ER stress signaling pathway, the genes ATF6, WFS1, $\mathrm{CHOP} 2, \mathrm{Bcl} 2$, and Bax were differentially expressed in the IRI/24 $\mathrm{h}$ group, as detected by RNA sequencing. In the autophagy pathway, the expression of ATG3 and ATG12 was significantly increased at $24 \mathrm{~h}$ post-reperfusion. These results suggest that signaling pathways containing
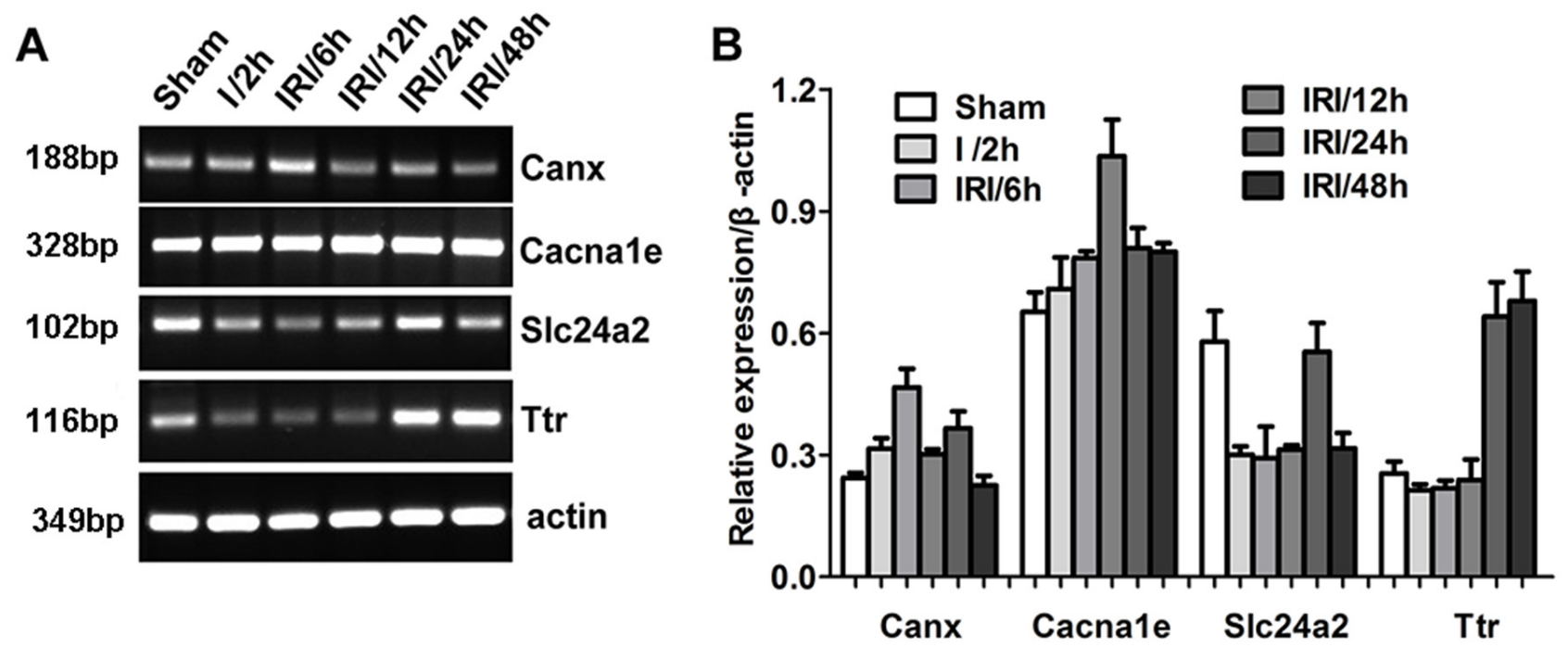

Figure 5: Differential gene expression at different reperfusion times was detected by RNA sequencing. (Panel A) Representative images of RT-PCR demonstrating differential gene expression. (Panel B) Quantitative analysis of gene expression. 
different genes were actived or inhibited in the process of IRI.

\section{DISCUSSION}

The MCAO is a universal model used to establish a focal cerebral IRI without the need for a craniotomy operation. This model enables accurate control of ischemia-reperfusion time. Previous experiments in our lab confirmed other reports [12] that transient cerebral ischemic injury for $2 \mathrm{~h}$ followed by post-reperfusion measurements at $24 \mathrm{~h}$ provides the most appropriate model of IRI. Accordingly, $2 \mathrm{~h}$ of ischemia followed by analysis of hippocampi sampled at $24 \mathrm{~h}$ post-reperfusion were the conditions under which abnormal expression of genes was evaluated.

It has been previously established that genes related to inflammation, apoptosis, proliferation, cell cycle, ER stress, and autophagy [13-16] are involved in the cellular events observed in cerebral IRI. Our results obtained from RNA sequencing were similar to those of previous studies, and draw a consistent conclusion regarding the genes involved in IRI.
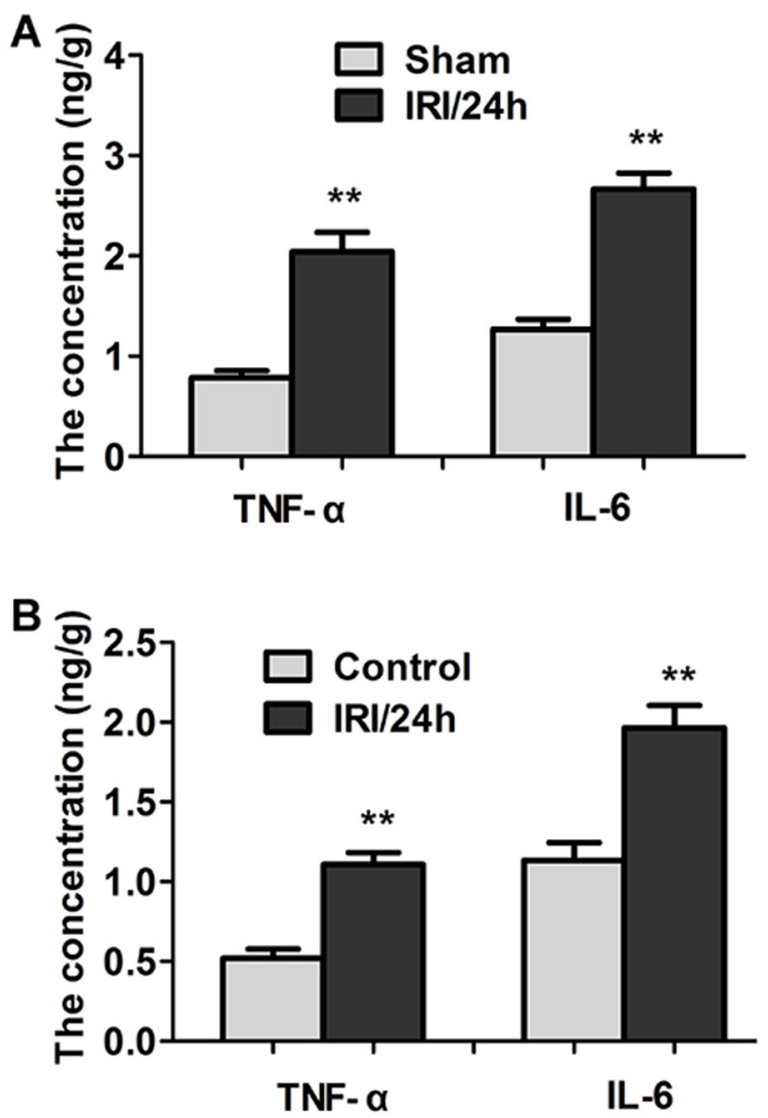

The expression of inflammatory factors was increased in the pathological process of cerebral IRI. The release of inflammatory molecules, including TNF- $\alpha$, IL$1 \beta$, IL- $6, \mathrm{NF}-\kappa \mathrm{B}$, and TGF- $\beta$, likely further aggravates cell injury during ischemia-reperfusion $[17,18]$. Consistent with previous studies in rat and cell models, IRI significantly induced the increased expression of TNF- $\alpha$, IL-6, and intercellular adhesion molecule (ICAM1), indicating that the inflammatory response was actived by cerebral IRI. Specific molecules that bind neutrophils, including CAMs and selectins (ICAM2, ICAM4, ICAM5, VCAM, selectin E, and selectin L), exhibited abnormal expression in our experiment. These genes play an important role in leukocyte infiltration and transmigration [19]. Gfap is a strong marker of gliosis, and may also serve as a marker of neuroinflammation $[20,21]$. In the current study, the expression of Gfap was up-regulated 2.286-fold (Table 3 ). This suggests that the over-activation of glia may be induced during IRI.

Cellular apoptosis may accompany cerebral IRI due to the expression of apoptosis-related genes [22, 23]. Bcl2 , a key antiapoptotic factor, could inhibit the release of cytochrome c. Bax, as a proapoptotic factor, may increase
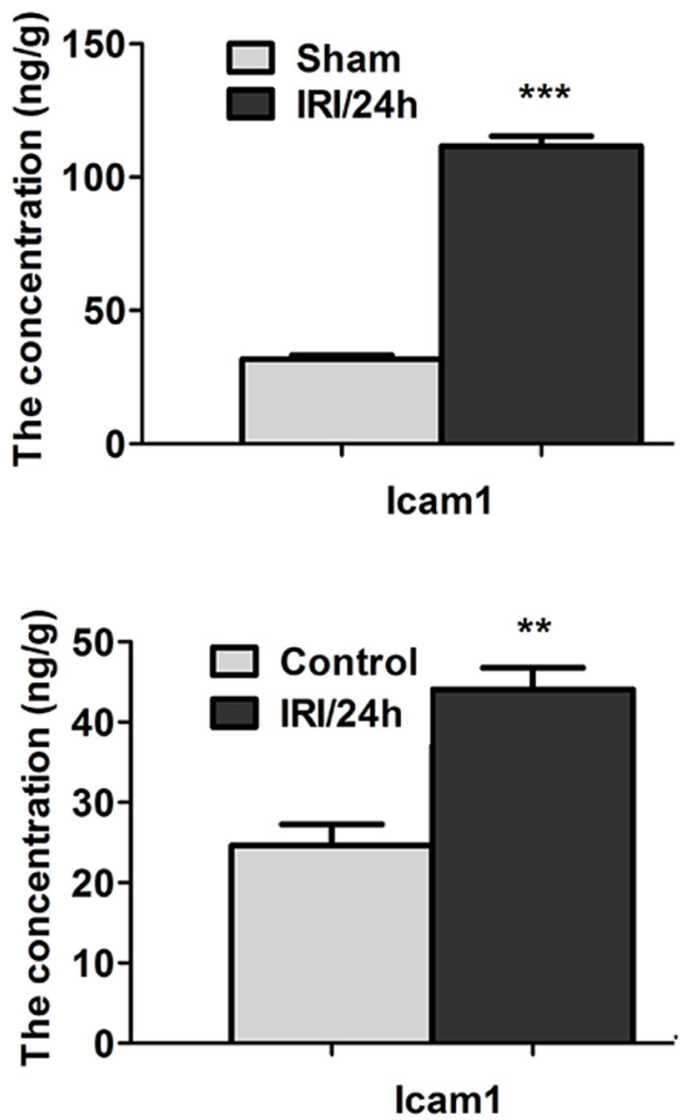

Figure 6: TNF- $\alpha$, IL-6, and ICAM-1 levels were detected by ELISA. (Panel A) TNF- $\alpha$, IL-6, and ICAM-1 levels in hippocampi of sham and IRI/24 h groups. (Panel B) TNF- $\alpha$, IL-6, and ICAM-1 levels in the control and the OGD cell model. The levels of TNF- $\alpha$, IL6, and ICAM-1 were significantly increased in the ischemia-reperfusion group compared with the sham group. $* * P<0.01, * * * P<0.001$. 
Table 4: Gene ontology classification of differentially expressed genes

\begin{tabular}{|c|c|c|c|}
\hline GO term & Input symbol & Expression & P-value \\
\hline \multicolumn{4}{|l|}{ Biological process } \\
\hline GO:0050896//response to stimulus & Atf3 & up & $5.20 \mathrm{E}-08$ \\
\hline GO:0006950//response to stress & $\operatorname{Ssc} 5 d$ & up & $6.23 \mathrm{E}-16$ \\
\hline GO:0019538//protein metabolic process & Olr1 & up & $6.20 \mathrm{E}-06$ \\
\hline GO:0006952//defense response & Lgals3 & up & 4.12E-06 \\
\hline GO:0006954//inflammatory response & Myd88 & up & $6.79 \mathrm{E}-07$ \\
\hline GO:0048869//cellular developmental process & Sema3d & up & $8.52 \mathrm{E}-06$ \\
\hline GO:0007154//cell communication & Nts & down & $1.15 \mathrm{E}-26$ \\
\hline GO:0006984//ER-nucleus signaling pathway & Wfs 1 & down & $2.06 \mathrm{E}-07$ \\
\hline GO:0007159//leukocyte cell-cell adhesion & Selplg & down & $5.65 \mathrm{E}-14$ \\
\hline GO:0008152//metabolic process & Pter & down & $6.51 \mathrm{E}-10$ \\
\hline \multicolumn{4}{|l|}{ Molecular function } \\
\hline GO:0019887//protein kinase regulator activity & Socs3 & up & $6.07 \mathrm{E}-12$ \\
\hline GO:0005198//structural molecule activity & Gfap & up & 0 \\
\hline GO:0003824//catalytic activity & Pla1a & up & $1.05 \mathrm{E}-07$ \\
\hline GO:0005216//ion channel activity & Piezo1 & up & $3.45 \mathrm{E}-08$ \\
\hline GO:0005520//insulin-like growth factor binding & Igfbp2 & up & $2.03 \mathrm{E}-11$ \\
\hline GO:0038023//signaling receptor activity & $\mathrm{Cd} 3 \mathrm{e}$ & down & $6.23 \mathrm{E}-08$ \\
\hline GO:0097367//carbohydrate derivative binding & Fibcd1 & down & $1.53 \mathrm{E}-31$ \\
\hline \multicolumn{4}{|l|}{ Cellular components } \\
\hline GO:0032991//macromolecular complex & Tubb6 & up & $6.83 \mathrm{E}-23$ \\
\hline GO:0043229//intracellular organelle & Slc1a4 & up & $1.72 \mathrm{E}-09$ \\
\hline GO:0031966//mitochondrial membrane & Tspo & up & $5.40 \mathrm{E}-06$ \\
\hline GO:0042101//T cell receptor complex & $\mathrm{Cd} 3 \mathrm{e}$ & down & $6.23 \mathrm{E}-08$ \\
\hline GO:0031224//component of membrane & Siglec5 & down & 4.08E-06 \\
\hline
\end{tabular}

the release of cytochrome c. Various reports suggest that Bcl-2 expression is decreased and Bax expression is increased at different reperfusion times [24, 25]. Consistent with these results, we demonstrated that Bcl-2 expression was decreased and Bax expression was increased in the hippocampus at $24 \mathrm{~h}$ post-reperfusion, as measured by RNA sequencing and RT-PCR. The differential expression of other genes related to apoptosis, including Bad, Bcl-6, Bak, Bcl2-like 1-15 (apoptosis facilitator), Bcl2-associated factors, and Bag (BCL2-associated athanogene), was detected through RNA sequencing. The expression of Caspase family members was also altered. Caspase-4, Caspase-7, and Caspase-8 exhibited 4.19-, 2.19-, and 1.57fold increases, respectively, indicating that these genes may involve in IRI.

Hsps are ubiquitous and highly conserved proteins that are induced in response to stressors including high temperature, ischemia, hypoxia, and pathological state
$[26,27]$. Hsps may be induced after cerebral ischemia, and their expression may protect against cellular damage via anti-inflammatory and antiapoptotic mechanisms, or the repair of damaged molecules [28-30]. In the present study, Hspb1, Hspala, and Hspalb were significantly increased at $24 \mathrm{~h}$ post-reperfusion in cellular and rat models. It is essential to further research the function of these genes to fully understand the mechanism of IRI.

Wolfram syndrome 1 (Wfs1) and activating transcription factor $6 \alpha$ (Atf6 $\alpha)$ are transmembrane proteins localized to the ER $[31,32]$. Wfs 1 negatively regulates Atf6 $\alpha$ through the ubiquitin-proteasome pathway. Wfs 1 stabilizes the E3 ubiquitin ligase HRD1, leading to the suppression of ER stress signaling. In the current study, we further verified the inverse relationship between Wfs 1 and Atf6. The expression level of Wfs 1 was significantly decreased, but Atf6 and Chop2 expression levels were significantly increased. This indicates that cerebral IRI 
Table 5: KEGG pathway classification of differentially expressed genes

\begin{tabular}{lccc}
\hline Pathway & Genes & P-value & Pathway ID \\
\hline Focal adhesion & Itga, Dock1, Rock, Rtk & $2.094476 \mathrm{e}-05$ & ko04510 \\
Regulation of actin cytoskeleton & Pxn, Rock, Itg, Limk, & 0.002440363 & ko04810 \\
Cytokine-cytokine receptor interaction & Arp2/3 & 0.0009153268 & ko04060 \\
Phagosome & Lxcl16, cl2, Sf1a & 0.0009153268 & ko04060 \\
MAPK signaling pathway & Tubb, MhcII, aMß2 & 0.001802472 & ko04145 \\
Jak-STAT signaling pathway & Fgfr, Hsp72, c-fos & 0.001802472 & ko04010 \\
Cell adhesion molecules & STAT, Myc, Socs & 0.001047253 & ko04630 \\
Toll-like receptor signaling pathway & Itgb2, Selplg, Ptprf & 0.001865349 & ko04514 \\
ER stress & Lbp, Opn, Myd88 & 0.001876453 & ko04620 \\
\hline
\end{tabular}

induces a decrease in Wfs 1 expression, which in turn activates the Atf-Chop pathway (Figure 8A). Previous reports [24] demonstrated that extended periods of ER stress activate Caspase-12, leading to cell death. Our results confirm these reports. Expression of Caspase-12 increased 3.59-fold based on RNA-sequencing analysis, and 2.85-fold based on RT-PCR analysis. These results suggest that ER stress is involved in cerebral IRI.
Previous reports established a connection between cerebral IRI and the activation of autophagy [33, 34]. Autophagy is a conserved homeostatic process that maintains cellular balance through the lysosomal system $[35,36]$. In normal physiological processes, misfolded molecules or damaged organelles are eliminated through autophagy. However, non-apoptotic programmed cell death is initiated through excessive self-digestion and

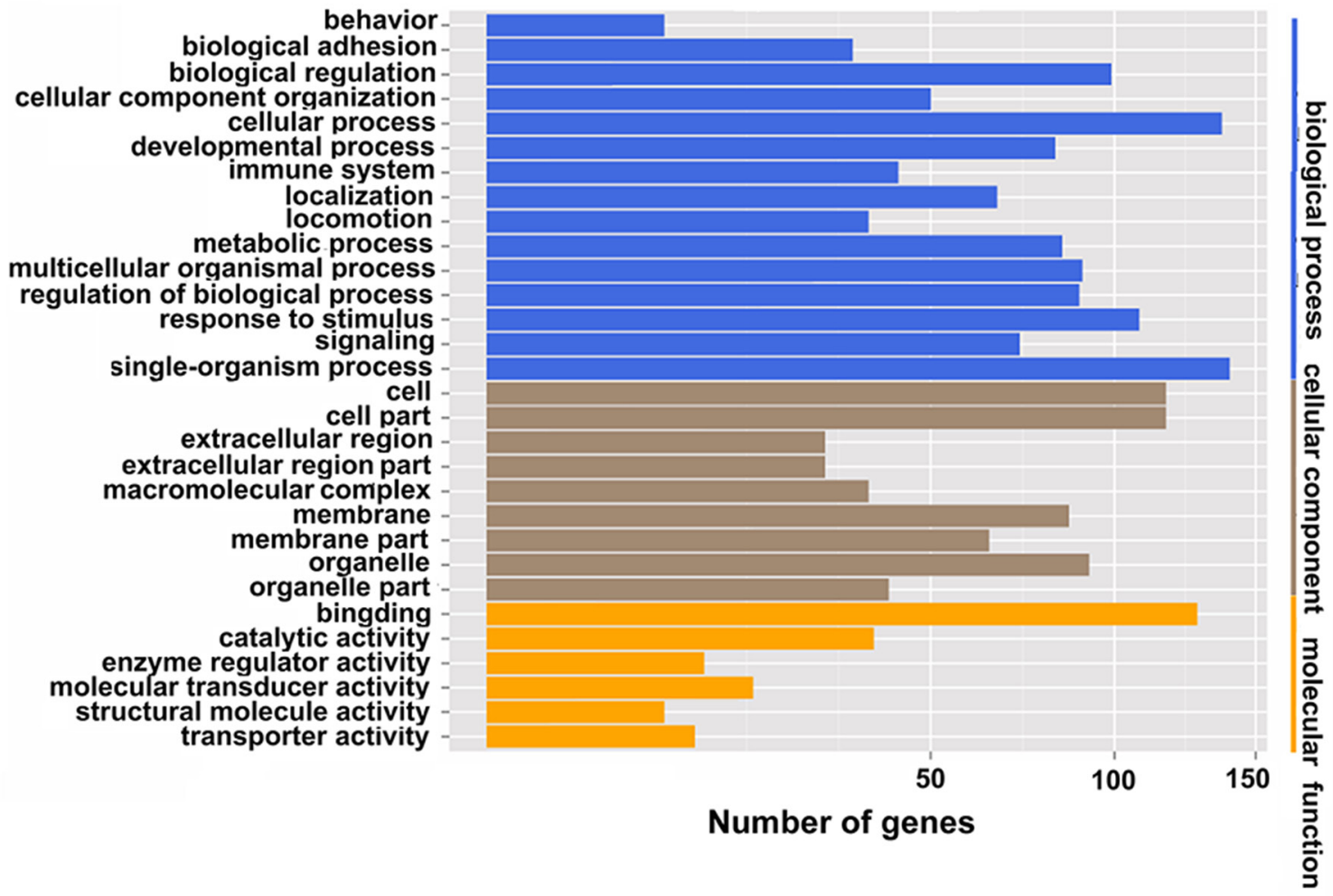

Figure 7: GO functional classification of IRI and sham groups. Blue denotes biological process; brown denotes cellular component; yellow denotes molecular function. 

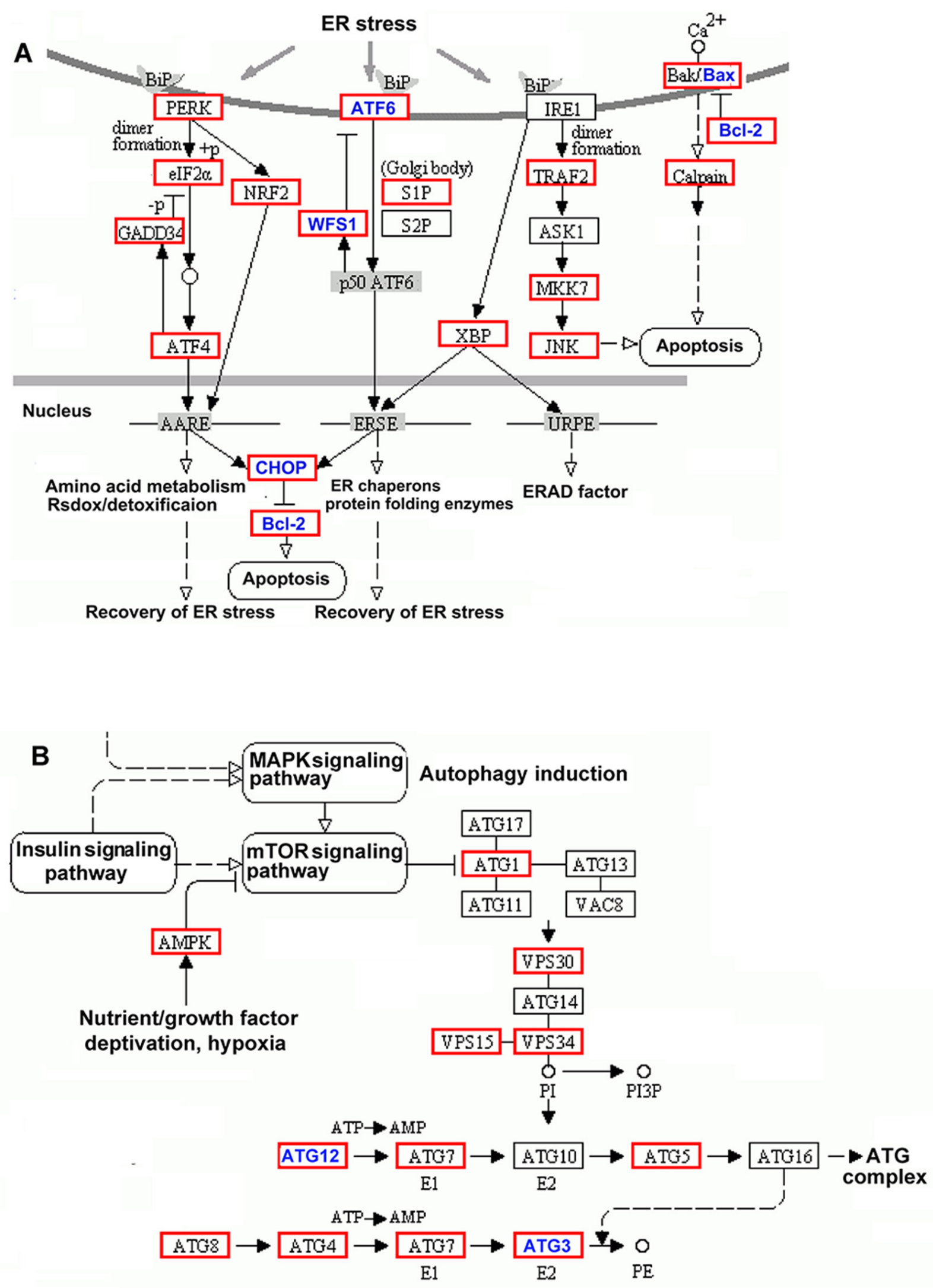

Figure 8: KEGG pathway classification of differentially expressed genes. (Panel A) ER stress signaling pathway. Blue denotes differentially expressed genes in ER stress signaling pathways. (Panel B) Autophagy pathway. Blue denotes differentially expressed genes in autophagy pathways. 
degradation of cellular components if autophagy is activated inappropriately $[37,38]$. Both cerebral ischemia and ischemia-reperfusion can activate autophagy by inducing high expression of certain genes, including Becn1, LC3-II, and Atg5 [39, 40]. To assess the level of autophagy after cerebral ischemia-reperfusion, we carried out global gene profiling using RNA sequencing. We found abnormal levels of calreticulin, Atg3, Atg12, Becn1, Atg5, and Uk11. Calreticulin, Atg3, and Atg12 were selected for amplification using RT-PCR. Consistent with the results obtained from RNA sequencing, these genes were dramatically elevated $24 \mathrm{~h}$ post-reperfusion. These results suggest that autophagy was over-activated by cerebral IRI.

Reperfusion after ischemic injury may give rise to two openings of the blood-brain barrier (BBB) during the refractory period [41]. The initial opening phase occurs several hours post-reperfusion and is transient. An irreversible second phase opening occurs $24 \mathrm{~h}$ to $72 \mathrm{~h}$ post-reperfusion. Consistent with this pathological phenomenon, a therapeutic strategy for ischemic stroke should be carried out as early as possible. In the present study, Canx, Cacna1e, Slc24a2, and Ttr were selected, and their expression levels were examined at 6, 12, 24, and $48 \mathrm{~h}$ after reperfusion. The expression of these genes was dynamic during the $48 \mathrm{~h}$ following reperfusion, and the peak expression time of each gene was not identical. This suggests that these genes play different role in IRI at different times following ischemia-reperfusion, underscoring the idea that the pathological processes of IRI are complex and diverse.

In summary, a global gene expression profile for the hippocampus after cerebral IRI was obtained using RNA sequencing. 156 genes were up-regulated and 26 genes were down-regulated. GO analysis and KEGG pathway analysis suggested that differentially expressed genes were involved in inflammation, oxidative stress, ER stress, apoptosis, autophagy, and metabolism. This study provides new insights into understanding the complicated molecular mechanisms of cerebral IRI. Further elaboration of the differentially expressed genes and relevant pathways will be beneficial for the prevention and treatment of cerebral IRI.

\section{MATERIALS AND METHODS}

\section{Experimental animals}

Male Wistar rats, aged 6-8 weeks, weighing 230 $280 \mathrm{~g}$, were purchased from Pengyue Experimental Animal Breeding Institute of Jinan, China (license no. SCXK (Lu) 2014-0007). The rats were housed in a controlled environment of $22-26^{\circ} \mathrm{C}, 50-60 \%$ humidity, and a $12 \mathrm{~h}$ light/dark cycle. All animal experiments were approved by the Ethics Committee of Jining Medical University and performed in accordance with the international Health Guide for the Care and Use of Laboratory Animals.

\section{Middle cerebral artery occlusion (MCAO) model}

The rat middle cerebral artery occlusion (MCAO) model was established as follows: Rats were anesthetized using $10 \%$ chloral hydrate $(0.3 \mathrm{~mL} / 100 \mathrm{~g})$ through intraperitoneal injection, and fixed in the supine position. The right common carotid artery was isolated, and a 0.26 $\mathrm{mm}$ diameter fishing line was inserted along the right common carotid arteries into the internal carotid artery until it blocked the origin of the middle cerebral artery. The depth of penetration was approximately $18 \mathrm{~mm}$. The incision was sutured. According to the experimental protocol of our lab [10,42], rats were subjected to focal ischemia for $2 \mathrm{~h}$, and the fishing lines were pulled out post-reperfusion at $2,6,12,24$, and $48 \mathrm{~h}$. In the sham group, the right carotid artery was isolated without occlusion of the common carotid arteries. The surgery was performed at $22 \pm 2{ }^{\circ} \mathrm{C}$. A neurological score was used to evaluate the success of the model. After the neurological score was obtained, the qualifying rats in each group were decapitated, and their hippocampi were isolated and stored on ice for use in the experiments described below.

\section{2, 3, 5-Triphenyl-2H-tetrazolium chloride (TTC) staining}

Brains were isolated from the $24 \mathrm{~h}$ post-reperfusion (IRI/24 h) group and the sham group. Brains were sliced into 2-mm-thick coronal sections. Tissue sections were incubated for $30 \mathrm{~min}$ at $37^{\circ} \mathrm{C}$ in $1 \%$ 2, 3, 5-triphenyl-2Htetrazolium chloride (TTC) solution (Sigma, St. Louis, MO, USA) in the dark. Slices were then collected for imaging. Infarct volume was determined using Image-Pro Plus v 6.0 software. Infarct volume ratio was calculated using the following formula: Infarct volume ratio $=(\Sigma$ infarct area $\times$ thickness $) /(\Sigma$ brain slices area $\times$ thickness $)$ $\times 100 \%$.

\section{RNA extraction and sequencing}

Total RNA from the IRI/24 h and sham groups was extracted using Trizol reagent (Invitrogen, Carlsbad, USA) and treated with DNase I to degrade contaminating DNA. The quality and concentration of the RNA was evaluated using agarose gel electrophoresis and the BioSpec-nano spectrophotometer (Shimadzu, Japan). Total mRNA was then isolated using oligo (dT), and fragmented into short fragments. First and second strand cDNA synthesis was carried out on individual mRNAs. Double-stranded cDNA was purified and modified with end repair, 3'-end single nucleotide adenine (A) addition, and sequencing adaptors. Finally, the fragments were enriched by PCR amplification to construct a library ready for sequencing using Illumina 
HiSeq TM 2000 in Shenzhen Huada Genetics Corporation (Shenzhen, China).

\section{Bioinformatics analysis}

Primary sequencing data produced by RNA sequencing, called raw reads, were subjected to quality control (QC). After QC, raw reads were filtered into clean reads. QC of alignment was performed to determine if re-sequencing was needed. If the alignment result passed QC, downstream analysis including gene expression, differentially expressed genes, cluster analysis, Gene Ontology (GO) enrichment analysis, and pathway enrichment analysis was proceeded with.

\section{Cluster analysis}

Distances of expressed genes were calculated using the Euclidean method. The sum of the squared deviations algorithm was used to calculate distance. The cluster analysis of gene expression patterns was performed using java Treeview software.

\section{Screening of differentially expressed genes}

To identify differentially expressed genes when comparing the IRI/24 $\mathrm{h}$ and sham groups, the Bonferroni correction was performed on P-values. The thresholds required for the results to be considered significant were as follows: FDR $\leq 0.001$ and absolute value of $\log ^{2}$ Ratio $\geq 1$.

\section{Semi-quantitative PCR}

The extracted total RNA was reverse-transcribed into cDNA using the FastQuant RT kit (Tiangen Biotech, Beijing, China). The cDNAs were then used in amplification reactions with $2 \times$ Taq PCR Master Mix (Tiangen Biotech, Beijing, China). $\beta$-actin was used as an internal reference gene. The reaction parameters were as follows: $94^{\circ} \mathrm{C}$ for $3 \mathrm{~min}$, followed by $30 \mathrm{cycles}$ at $94^{\circ} \mathrm{C}$ for $40 \mathrm{sec}, 55^{\circ} \mathrm{C}$ for $50 \mathrm{sec}$, and $72^{\circ} \mathrm{C}$ for $50 \mathrm{sec}$. The amplification products were separated by electrophoresis on a $1 \%$ agarose gel, and analyzed using Image $2 \mathrm{x}$ software.

\section{Oxygen-glucose deprivation (OGD) model}

SHY-5Y cells were purchased from the Cell Resource Center of the Chinese Academy of Sciences (Shanghai, China). Cells were grown in DMEM medium supplemented with $10 \% \mathrm{FBS}, 100 \mathrm{U} / \mathrm{mL}$ penicillin, and $100 \mu \mathrm{g} / \mathrm{mL}$ streptomycin in a humidified atmosphere of $5 \% \mathrm{CO}_{2}$ at $37^{\circ} \mathrm{C}$. For the oxygen-glucose deprivation (OGD) model, SHY-5Y cells were divided into two groups: (1) Control group: Cells were cultured in DMEM without OGD; (2) OGD model group: Cells were incubated in Eagle's medium for $2 \mathrm{~h}$ at $37^{\circ} \mathrm{C}$ in an incubator under $5 \% \mathrm{O}_{2}, 5 \% \mathrm{CO}_{2}$, and $90 \% \mathrm{~N}_{2}$. Cells were then cultured in fresh medium for $24 \mathrm{~h}$ at $37^{\circ} \mathrm{C}$ in an incubator under $5 \% \mathrm{CO}_{2}$.

\section{Enzyme-linked immunosorbent assay (ELISA)}

Homogenates of hippocampi from IRI/24 $\mathrm{h}$ and sham groups were made and centrifuged at $4^{\circ} \mathrm{C}$. The supernatants were collected, and used to detect the levels of TNF- $\alpha$, IL-6, and ICAM-1 using enzyme-linked immunosorbent assay (ELISA) kits from Cloud-Clone Corp. (Wuhan, China), according to the manufacturer's instructions. All ELISA analyses were carried out in triplicate. The concentrations of TNF- $\alpha$, IL- 6 , and ICAM1 were determined according to a standard curve.

\section{GO enrichment analysis}

GO enrichment was used to note the function of differentially expressed genes via the GO database (http://www.geneontology.org/). A Bonferroni correction was used to obtain a corrected P-value. GO terms with $\mathrm{P}$-values $\geq 0.5$ were regarded as significantly enriched in the target candidates. After obtaining GO annotation for differentially expressed genes, WEGO software was used for GO functional classification of differentially expressed genes [43].

\section{Kyoto encyclopedia of genes and genomes (KEGG) pathway analysis}

The Kyoto Encyclopedia of Genes and Genomes (KEGG) pathway database (http://www.genome.jp/ $\mathrm{kegg} /$ ) was used to determine pathway enrichment of differentially expressed genes compared with the reference gene background. Genes with FDR $\leq 0.05$ were regarded as significantly enriched. In addition, a scatter plot for KEGG enrichment results was generated.

\section{Statistical analysis}

All data were presented as mean \pm SEM and analyzed using GraphPad Prism 5.0 software. Significance was determined using Student's t-test. Differences between group means with $P<0.05$ were considered statistically significant.

\section{ACKNOWLEDGMENTS}

We are thankful for the support provided by grants from National Nature Science Foundation of China (nos. 81501018; 31271243), and Shandong Province Natural Science Foundation (nos. ZR2013CQ031; ZR2015CL021).

\section{CONFLICTS OF INTEREST}

The authors declare that they have no conflicts of interest and no competing financial interests. 


\section{REFERENCES}

1. Alexandrov AV, Hall CE, Labiche LA, Wojner AW, Grotta JC. Ischemic stunning of the brain: early recanalization without immediate clinical improvement in acute ischemic stroke. Stroke. 2004; 35:449-452.

2. Lopes RD, Piccini JP, Hylek EM, Granger CB, Alexander $\mathrm{JH}$. Antithrombotic therapy in atrial fibrillation: guidelines translated for the clinician. J Thromb Thrombolysis. 2008; 26:167-174.

3. Hacke W, Schwab S, Horn M, Spranger M, De Georgia M, von Kummer R. 'Malignant' middle cerebral artery territory infarction: clinical course and prognostic signs. Arch Neurol. 1996; 53:309-315.

4. Nour M, Scalzo F, Liebeskind DS. Ischemia-reperfusion injury in stroke. Interv Neurol. 2013; 1:185-199.

5. White BC, Sullivan JM, DeGracia DJ, O'Neil BJ, Neumar RW, Grossman LI, Rafols JA, Krause GS. Brain ischemia and reperfusion: molecular mechanisms of neuronal injury. J Neurol Sci. 2000; 179:1-33.

6. Kitamura A, Fujita Y, Oishi N, Kalaria RN, Washida K, Maki T, Okamoto Y, Hase Y, Yamada M, Takahashi J, Ito H, Tomimoto H, Fukuyama H, et al. Selective white matter abnormalities in a novel rat model of vascular dementia. Neurobiol Aging. 2012; 33:1012.e1025-1035.

7. Gong X, Ma M, Fan X, Li M, Liu Q, Liu X, Xu G. Downregulation of igf-1/igf-1r in hippocampus of rats with vascular dementia. Neurosci Lett. 2012; 513:20-24.

8. Leak RK, Zhang L, Stetler RA, Weng Z, Li P, Atkins GB, Gao Y, Chen J. Hsp27 protects the blood-brain barrier against ischemia-induced loss of integrity. CNS Neurol Disord Drug Targets. 2013; 12:325-337.

9. Tian D, Litvak V, Lev S. Cerebral ischemia and seizures induce tyrosine phosphorylation of pyk2 in neurons and microglial cells. J Neurosci. 2000; 20:6478-6487.

10. Xin Q, Cheng B, Pan Y, Liu H, Yang C, Chen J, Bai B. Neuroprotective effects of apelin-13 on experimental ischemic stroke through suppression of inflammation. Peptides. 2014; 63:55-62.

11. Wu L, Feng XT, Hu YQ, Tang N, Zhao QS, Li TW, Li HY, Wang QB, Bi XY, Cai XK. Global gene expression profile of the hippocampus in a rat model of vascular dementia. Tohoku J Exp Med. 2015; 237:57-67.

12. Liu G, Song J, Guo Y, Wang T, Zhou Z. Astragalus injection protects cerebral ischemic injury by inhibiting neuronal apoptosis and the expression of jnk3 after cerebral ischemia reperfusion in rats. Behav Brain Funct. 2013; 9:36.

13. Yu Z, Liu J, Guo S, Xing C, Fan X, Ning M, Yuan JC, Lo EH, Wang X. Neuroglobin-overexpression alters hypoxic response gene expression in primary neuron culture following oxygen glucose deprivation. Neuroscience. 2009; 162:396-403.

14. Wang L, Liu H, Zhang L, Wang G, Zhang M, Yu Y. Neuroprotection of dexmedetomidine against cerebral ischemia-reperfusion injury in rats: involved in inhibition of NF- $\kappa \mathrm{B}$ and inflammation response. Biomol Ther (Seoul). $2017 ; 25: 383-389$.

15. Zhang ZG, Sun X, Zhang QZ, Yang H. Neuroprotective effects of ultra-low-molecular-weight heparin on cerebral ischemia/reperfusion injury in rats: involvement of apoptosis, inflammatory reaction and energy metabolism. Int J Mol Sci. 2013; 14:1932-1939.

16. Ouyang L, Shi Z, Zhao S, Wang FT, Zhou TT, Liu B, Bao JK. Programmed cell death pathways in cancer: a review of apoptosis, autophagy and programmed necrosis. Cell Prolif. 2012; 45:487-498.

17. Ritter LS, Orozco JA, Coull BM, McDonagh PF, Rosenblum WI. Leukocyte accumulation and hemodynamic changes in the cerebral microcirculation during early reperfusion after stroke. Stroke. 2000; 31:1153-1161.

18. Yasuda Y, Shimoda T, Uno K, Tateishi N, Furuya S, Tsuchihashi Y, Kawai Y, Naruse S, Fujita S. Temporal and sequential changes of glial cells and cytokine expression during neuronal degeneration after transient global ischemia in rats. J Neuroinflammation. 2011; 8:70.

19. Anuncibay-Soto B, Perez-Rodriguez D, Llorente IL, Regueiro-Purrinos M, Gonzalo-Orden JM, FernandezLopez A. Age-dependent modifications in vascular adhesion molecules and apoptosis after 48-h reperfusion in a rat global cerebral ischemia model. Age (Dordr). 2014; 36:9703.

20. Busch SA, Silver J. The role of extracellular matrix in cns regeneration. Curr Opin Neurobiol. 2007; 17:120-127.

21. Rolls A, Shechter R, Schwartz M. The bright side of the glial scar in cns repair. Nat Rev Neurosci. 2009; 10:235-241.

22. Cregan SP, Fortin A, MacLaurin JG, Callaghan SM, Cecconi F, Yu SW, Dawson TM, Dawson VL, Park DS, Kroemer G, Slack RS. Apoptosis-inducing factor is involved in the regulation of caspase-independent neuronal cell death. J Cell Biol. 2002; 158:507-517.

23. Liu G, Wang T, Wang T, Song J, Zhou Z. Effects of apoptosis-related proteins caspase-3, bax and bcl-2 on cerebral ischemia rats. Biomed Rep. 2013; 1:861-867.

24. Xing B, Chen H, Zhang M, Zhao D, Jiang R, Liu X, Zhang $\mathrm{S}$. Ischemic postconditioning inhibits apoptosis after focal cerebral ischemia/reperfusion injury in the rat. Stroke. 2008; 39:2362-2369.

25. Aboutaleb N, Shamsaei N, Rajabi H, Khaksari M, Erfani S, Nikbakht F, Motamedi P, Shahbazi A. Protection of hippocampal cal neurons against ischemia/reperfusion injury by exercise preconditioning via modulation of bax/ bcl-2 ratio and prevention of caspase-3 activation. Basic Clin Neurosci. 2016; 7:21-29.

26. Williams RS. Heat shock proteins and ischemic injury to the myocardium. Circulation. 1997; 96:4138-4140.

27. Martin JL, Mestril R, Hilal-Dandan R, Brunton LL, Dillmann WH. Small heat shock proteins and protection 
against ischemic injury in cardiac myocytes. Circulation. 1997; 96:4343-4348.

28. Brown IR. Heat shock proteins and protection of the nervous system. Ann N Y Acad Sci. 2007; 1113:147-158.

29. Giffard RG, Yenari MA. Many mechanisms for hsp70 protection from cerebral ischemia. J Neurosurg Anesthesiol. 2004; 16:53-61.

30. Zheng Z, Kim JY, Ma H, Lee JE, Yenari MA. Antiinflammatory effects of the $70 \mathrm{kda}$ heat shock protein in experimental stroke. J Cereb Blood Flow Metab. 2008; 28:53-63.

31. Takeda K, Inoue H, Tanizawa Y, Matsuzaki Y, Oba J, Watanabe Y, Shinoda K, Oka Y. Wfs1 (wolfram syndrome 1) gene product: predominant subcellular localization to endoplasmic reticulum in cultured cells and neuronal expression in rat brain. Hum Mol Genet. 2001; 10:477-484.

32. Fonseca SG, Ishigaki S, Oslowski CM, Lu S, Lipson KL, Ghosh R, Hayashi E, Ishihara H, Oka Y, Permutt MA, Urano F. Wolfram syndrome 1 gene negatively regulates er stress signaling in rodent and human cells. J Clin Invest. 2010; 120:744-755.

33. Zheng Y, Hou J, Liu J, Yao M, Li L, Zhang B, Zhu H, Wang Z. Inhibition of autophagy contributes to melatoninmediated neuroprotection against transient focal cerebral ischemia in rats. J Pharmacol Sci. 2014; 124:354-364.

34. Yang X, Hei C, Liu P, Song Y, Thomas T, Tshimanga S, Wang F, Niu J, Sun T, Li PA. Inhibition of mtor pathway by rapamycin reduces brain damage in rats subjected to transient forebrain ischemia. Int J Biol Sci. 2015; 11:1424-1435.
35. Marino G, Madeo F, Kroemer G. Autophagy for tissue homeostasis and neuroprotection. Curr Opin Cell Biol. 2011; 23:198-206.

36. Wong E, Cuervo AM. Autophagy gone awry in neurodegenerative diseases. Nat Neurosci. 2010; 13:805-811.

37. Shintani T, Klionsky DJ. Autophagy in health and disease: a double-edged sword. Science. 2004; 306:990-995.

38. Uchiyama Y, Shibata M, Koike M, Yoshimura K, Sasaki M. Autophagy-physiology and pathophysiology. Histochem Cell Biol. 2008; 129:407-420.

39. Liu C, Gao Y, Barrett J, Hu B. Autophagy and protein aggregation after brain ischemia. J Neurochem. 2010; 115:68-78.

40. Luo T, Liu G, Ma H, Lu B, Xu H, Wang Y, Wu J, Ge P, Liang J. Inhibition of autophagy via activation of pi3k/akt pathway contributes to the protection of ginsenoside $\mathrm{rb} 1$ against neuronal death caused by ischemic insults. Int J Mol Sci. 2014; 15:15426-15442.

41. Kuroiwa T, Ting P, Martinez H, Klatzo I. The biphasic opening of the blood-brain barrier to proteins following temporary middle cerebral artery occlusion. Acta Neuropathol. 1985; 68:122-129.

42. Yan XG, Cheng BH, Wang X, Ding LC, Liu HQ, Chen J, Bai B. Lateral intracerebroventricular injection of apelin-13 inhibits apoptosis after cerebral ischemia/reperfusion injury. Neural Regen Res. 2015; 10:766-771.

43. Ye J, Fang L, Zheng H, Zhang Y, Chen J, Zhang Z, Wang J, Li S, Li R, Bolund L, Wang J. Wego: a web tool for plotting go annotations. Nucleic Acids Res. 2006; 34:W293-297. 